\title{
Cuidado em território de exclusão social: covid-19 expõe marcas coloniais'
}

\section{Care in a territory of social exclusion: covid-19 exposes colonial marks}

\author{
Claudia Camilo \\ (D) https://orcid.org/0000-0003-2882-2041 \\ E-mail: camilo.claudiaœunifesp.br

\section{Edna Kahhale} \\ (D) https://orcid.org/0000-0002-8711-2931 \\ E-mail: ednapeterskahhaleœgmail.com

\section{Maria Luísa Ferreirac \\ E-mail: luisarifeळsapo.pt \\ Mariana Schveitzer ${ }^{d}$ \\ (D) https://orcid.org/0000-0001-9833-2932 \\ E-mail: mariana.cabralळunifesp.br} \\ (D) https://orcid.org/0000-0003-3355-8572
}

aniversidade Federal de São Paulo. Instituto de Saúde e Sociedade. Programa de Pós-Graduação Interdisciplinar em Ciências da Saúde. Santos, SP, Brasil.

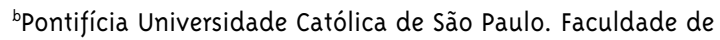
Ciências Humanas e da Saúde. Departamento de Psicologia Social. São Paulo, SP, Brasil.

'Universidade de Lisboa. Centro de Filosofia. Lisboa, Portugal. ¿Universidade Federal de São Paulo. Escola Paulista de Medicina. Departamento de Medicina Preventiva. São Paulo, SP, Brasil.

\section{Resumo}

A intersecção de gênero, raça e classe marca os territórios de exclusão social, especialmente em um país que carrega cicatrizes da colonialidade patriarcal e capitalista em suas estruturas, como é o caso do Brasil. O objetivo deste trabalho é compreender o cuidado em um desses territórios: a cidade de Cubatão/SP. A investigação, feita entre 2017 e 2020, incluiu a pandemia da covid-19, que sobrecarregou o cuidado no território. 0 método foi a pesquisa qualitativa, com oficinas, observação participante e entrevistas de profundidade. 0 cuidado era majoritariamente oferecido por mulheres, líderes comunitárias e profissionais da atenção primária do Sistema Único de Saúde. Para analisar os dados, utilizou-se a hermenêutica de profundidade. O referencial teórico foi a costura das teorias feministas da ética do cuidado, ecofeministas e interseccionais. A pesquisa revelou diversos desafios e potencialidades, como o cuidado ético-político, eixo da busca por justiça socioambiental.

Palavras-chave: Ética do Cuidado; Políticas Públicas; Exclusão Social; Interseccionalidade; Covid-19.

\section{Correspondência}

Claudia Camilo

Av. Ana Costa, 95. Santos, SP, Brasil. CEP I1060-00।.

\footnotetext{
1 Este estudo é um desdobramento das pesquisas "Ética do cuidado e construção de direitos: acolhimento psicossocial em práticas da saúde da família em situações de exclusão social” (fomentada pela Fundação de Amparo à Pesquisa do Estado de São Paulo (Fapesp), nº 2016/23973-2), "Desigualdade social e subjetividade: trajetórias de vida e lutas por melhores condições de vida e saúde em território vulnerável da Baixada Santista" (apoiada pelo Conselho Nacional de Desenvolvimento Científico e Tecnológico (CNPq), $\mathrm{n}^{0} 407836 / 2016$-o), que foram aprovadas pelo Comitê de Ética em Pesquisa da Universidade Federal de São Paulo, pareceres 2.198.202 e 2.047.444, e “Ética do cuidado e processos psicossociais de participação social em práticas da saúde da família em situações de exclusão social” (Bolsa Produtividade CNPq n 308730/2019-4).
} 
The intersection of gender, race and class marks the territories of social exclusion, especially in a country that carries scars of a patriarchal and capitalist colonialism in its structures, such as is the case in Brazil. The objective was to understand care in this territory of exclusion in Cubatão, São Paulo, Brazil. The research, conducted between 2017 and 2020, included the pandemic of COVID-19, which overloaded the care in this territory. The method was qualitative research, with workshops, participant observation and indepth interviews. The care performed by community leaders and primary health care professionals from the Unified Health System was mostly performed by women. For data analysis, the depth hermeneutics was used. The theoretical reference was the cut of feminists: ecofeminist, intersectional and Care Ethics. The study showed several challenges and the ethical-political care as an axis in the search for social and environmental justice.

Keywords: Ethics; Public Policy; Social Exclusion; Intersectionality; COVID-19.
Asociedade brasileira é marcada pela colonialidade, pelo patriarcalismo e pelo capitalismo (Chaui, 2009), marcas que deixam um grupo específico na base da pirâmide social: as mulheres, maioria da população brasileira, perfazendo um total de $52 \%$. Dentro desse grupo, as negras, "pardas" e indígenas ocupam os lugares mais baixos, enquanto, paralelamente, homens brancos, herdeiros de um patrimônio acumulado desde a escravidão, seguem no topo da pirâmide (Souza, 2019). Trata-se da "colonialidade", a inseparabilidade entre patriarcado, exploração capitalista, racialização e gênero (Lugones, 2014). Nesse processo de desumanização como estratégia de exploração, a objetificação é a investida para tornar o colonizado menos que ser humano (Lugones, 2014). Essas pessoas, hoje, vivem em territórios de alta exclusão social.

Nesses locais, a condição de não ter "posses" deixa a população em situação vulnerável ao capitalismo (Shiva, 1988), e esse é o caso do território de exclusão social aqui estudado, localizado em Cubatão, cidade da Baixada Santista, no estado de São Paulo. Nesse território, em terrenos expropriados, as pessoas constroem moradias frágeis, com risco de afundamento, sem energia elétrica e saneamento básico, vivendo com renda precária ou nula. Vivese sem direitos básicos, em um local abandonado pelo poder público, e grande parte das pessoas que aí vivem e prestam cuidado são mulheres negras.

Em um contexto como esse, de desigualdade social e interseccional de gênero, classe e raça (Hale, 2004), a garantia constitucional da saúde pública, gratuita e universal, por meio do Sistema Único de Saúde (SUS), foi um avanço. Assim, a atenção primária das unidades de saúde da família (USF) está presente nos territórios de exclusão social, realizando ações de cuidado integral por meio da Estratégia Saúde da Família (Brasil, 2012).

Em 2016, no entanto, foi aprovada a Emenda Constitucional $\mathrm{n}^{0} 95$ (EC 95), que congelou investimentos em saúde, ciência e educação

\footnotetext{
2 "Colonialidade" se refere a epistemes e práticas patriarcais eurocêntricas, usadas na pré-colônia, colônia e pós-colônia. "Descolonização" é a transição do período colonial para o pós-colonial. "Decolonialidade" é o processo contínuo de ruptura com a colonialidade que valoriza epistemes e práticas não eurocêntricas.
} 
por 20 anos. E justamente nessa conjuntura de desmonte social, a pandemia da covid- $19^{3}$ explicitou o erro da emenda, que agravou as feridas deixadas pelo colonialismo (Dantas, 2020). No território de exclusão estudado, houve aumento da população devido ao aumento do desemprego a partir de 2015 , com abrupto crescimento em 2020, que aguçou a crise socioeconômica, política e sanitária já existente (IBGE, 2020).

O território aqui estudado, fortemente atingido pela covid-19, teve suas mazelas e desafios intensificados, mas também mostrou potências perante a crise sociossanitária. O presente estudo resulta de pesquisa sobre o cuidado nessa comunidade. O arcabouço teórico é formado por teorias feministas da ética do cuidado, do ecofeminismo e da interseccionalidade que revigoram o cuidado ético-político, amparado pelo Estado democrático de direito e pelas políticas públicas a fim de diminuir as desigualdades e reparar as exclusões da colonialidade mantida pelo capitalismo neoliberal.

Pensar o cuidado em territórios com diversidades interseccionais requer uma costura de subjetividades. A categoria "cuidado" identifica-se na língua portuguesa com a ideia de atenção, empatia, zelo, responsabilidade, proteção e amor. Trata-se de afetos que se implicam a si mesmos, outras pessoas e o ambiente. 0 verbo "cuidar", em português arcaico, significava "amar, gostar de"; no tronco linguístico macro-jê, ${ }^{4}$ significa tiçuánácênató, "zelar”; no guarani (Mbyá) há “cuidar” (arõ, nhangareko, pena, ereko), "cuidar-se" (jepoyvu ou enênãntende em Kaiowá), "ficar cuidando" (pota) e "ter cuidado" (nheangu), denotando que há o cuidado de si próprio, o cuidado com o outro ou com o ambiente.

Na filosofia africana do ubuntu (origem bantu), a humanidade se relaciona com os outros: "eu sou, porque nós somos” (Carvalho, 2016). Ubuntu, portanto, sugere solidariedade, cooperação, respeito, acolhimento e generosidade, entre outras ações em sintonia consigo mesmo, com os outros e com o meio ambiente, em busca de bem-estar. Nelson Mandela sintetiza a antiga ética africana de que meu progresso pessoal está a serviço do progresso da minha comunidade, sendo isso o mais importante na vida e se uma pessoa conseguir viver assim, terá atingido algo admirável (Carvalho, 2016).

Quando considerado como responsabilidade, o cuidado é uma ação para a sobrevivência, e majoritariamente prestado por mulheres. Adentramos assim na "ética do cuidado", como cunhado por estudiosas feministas. Ao valorizar o trabalho de cuidado executado por mulheres, essas teóricas ressaltam a responsabilidade do cuidar de si, do outro e do ambiente, relacionando o cuidado à representação política, às políticas públicas e à democracia. Joan Tronto, por exemplo, em Caring democracy relaciona democracia e cuidado, observando uma relação interdependente: a busca por justiça deve ser discutida a partir de um elemento central, o cuidado (Mota, 2015).

Questionando, do ponto de vista moral, político e econômico, as estruturas patriarcais que desvalorizam o trabalho do cuidado, as teóricas feministas refletem sobre a possibilidade de um cuidado ético, que seja garantido como política pública. Delineia-se então a categoria de "cuidado ético-político", que conjuga ética e política de tal forma que não se pode pensar uma sem a outra (Pintasilgo, 2011).

Ante a colonialidade mantida pelo sistema capitalista neoliberal, que deixa as mulheres na base do cuidado, pensar a ética do cuidado requer considerar, além do gênero, imbricações de raça e classe, através da interseccionalidade proposta por feministas negras como Lélia Gonzalez (1984) e Beatriz Nascimento (2018), que propõem a inseparabilidade estrutural do patriarcado capitalista, machista e racista.

A “amefricanidade" proposta por Lélia Gonzalez na década de 1980 inspira a abordagem decolonial, consolidada nos anos 2000 por Catherine Walsh, María Lugones, Julieta Paredes e outras pensadoras latino-americanas que criticam a colonialidade, o neoliberalismo e monopólio epistêmico ocidental (Akotirene, 2019). Nos Estados Unidos, inspiradas em Gonzalez (1984), Kimberlé Crenshaw (1989), Angela Davis (2016) e Patricia Hill Collins (2017)

3 A Organização Mundial de Saúde descreve a pandemia da covid-19 como uma das maiores crises sanitárias das últimas décadas (WHO, 2020). 4 ISA - INSTITUTO SOCIOAMBIENTAL. Dicionário. 2020. Disponível em: <https://bit.ly/3uuRfAz〉. Acesso em: 9 out. 2020. 
pesquisam a interseccionalidade de gênero, raça e classe e se aprofundam no ativismo contra a matança e o encarceramento do povo negro. No Brasil, atualmente, Carla Akotirene (2019) resgata e reinterpreta o conceito para a realidade brasileira, no constante exercício decolonial.

O cuidado ético-político, como visto a partir de Nascimento (2018), aponta a saída para o modelo capitalista neoliberal da necropolítica (Mbembe, 2018) pelo exemplo dos quilombos, da união. Para citar um exemplo, foi uma mulher, Tereza de Benguela, uma das maiores governantes quilombolas da América Latina. Tereza cuidou da população que se libertou das atrocidades escravagistas e desenvolveu uma administração política, oferecendo um cuidado de caráter libertário, ético-político, comunitário e consciente. Um cuidado onde produção, distribuição e consumo são autogestionados; a política é democrática; os bens são distribuídos equitativamente; e humanos e ambiente são valorizados, como ocorre com os povos originários latino-americanos e africanos.

Vandana Shiva (1988), pelo ecofeminismo, propõe o cuidado socioambiental da casa comum. Ela ressalta o papel das mulheres na resistência à invasão dos grandes monopólios econômicos, patriarcais, e mostra saídas para combater a globalização neoliberal, que relega agricultores à pobreza e à dependência das empresas produtoras de grãos (Shiva, 1988). As populações que se alimentavam de milho, cultivado pelas mulheres, faziam suas casas, seu vestuário e nada consumiam das grandes empresas (Shiva, 1988). Esse tipo de cuidado socioambientalmente sustentável é proposto no Brasil pela economia solidária, que busca combater o desemprego e a desigualdade social (Singer; Souza, 20oo).

O presente estudo apresenta a hipótese de que o cuidado ultrapassa os equipamentos do SUS e é executado também pelas próprias famílias e líderes comunitárias, no espaço doméstico, igrejas, creches, escolas, organizações de base comunitária etc. Investigar o cuidado a partir dessa hipótese, antes e durante a pandemia da covid-19, contribuiu para verificar as políticas públicas no território de modo a valorizar, econômica e moralmente, o grupo que vem praticando o cuidado ao longo de toda a história: as mulheres. $\mathrm{O}$ objetivo foi compreender as facetas do cuidado nesse território de exclusão social afetado pela colonialidade mantida pelo capitalismo neoliberal, partindo da percepção de pessoas que resistem, cuidam e lutam por melhores condições de vida.

\section{Método}

A pesquisa qualitativa, realizada in loco, num território em que a Universidade Federal de São Paulo (Unifesp) atua com projetos, ações e pesquisas, contou com a escuta de narrativas mediante inserção de pesquisadores do Laboratório de Estudos sobre a Desigualdade (Leds). O critério de seleção dos participantes foi: residir no território e realizar práticas de cuidado. A aproximação e capilarização se deram a partir da USF do local. Ao todo, foram 11 os participantes da pesquisa: 8 agentes comunitários de saúde (6 mulheres e 2 homens) e 3 líderes comunitários ( 2 mulheres e 1 homem). Todos os cuidados éticos foram seguidos, e o estudo foi submetido a Comitê de Ética em Pesquisa da Unifesp.

Entre 2017 e 2020 , houve entrevistas de profundidade e oficinas com observação participante, e diários de campo foram produzidos. As entrevistas, conduzidas por seis membros do Leds, ocorreram inicialmente em situações de oficina e, após a chegada da pandemia, por meios remotos. As perguntas balizadoras eram: como você percebe a situação atual de vida aqui? Onde recebe cuidado? Você cuida de alguém? Quais tipos de cuidado você vê aqui? O que aconteceu depois da chegada da pandemia?

As entrevistas foram gravadas e transcritas digitalmente. Os dados, organizados no software Atlas.ti, que auxilia a sistematização em pesquisas qualitativas (Forte et al., 2017), passaram por leitura intensiva e tiveram trechos selecionados e classificados em códigos, agrupados em três zonas de sentido.

Amparada na hermenêutica de profundidade (Thompson, 2011), a análise tratou de múltiplas dimensões: o contexto sócio-histórico do território; a narrativa dos interlocutores; e a interpretação e reinterpretação das autoras. Assim, o método permitiu uma análise diversificada dos dados, capaz de relacionar a conjuntura do território, a fala das pessoas entrevistadas e o olhar das autoras, entrelaçando referências da ética do cuidado, da interseccionalidade e do ecofeminismo. 


\section{Discussão de resultados}

\section{Apresentação do território: situação interseccional, sócio-histórica e ambiental}

O sistema capitalista extrativista, patriarcal, machista e racista é representado por homens brancos que invadiram terras e enriqueceram utilizando mão de obra de pessoas negras, indígenas e mulheres, roubadas de suas culturas e escravizadas (Souza, 2019). Os excluídos sempre resistiram, construíram o país e, após a abolição, foram abandonados, sem habitação, renda, propriedade ou alimento, empurrados para "territórios de exclusão social” (Anhas; Silva, 2017).

A categoria "território de exclusão social" é explorada por Shiva (1988). A propriedade privada é uma categoria alheia às tradições indígenas, aborígenes, indianas, africanas, quilombolas e de outros povos que vivem em estruturas comunitárias. A privatização neoliberal, entretanto, exclui essas populações, realocando comunidades à força para territórios periféricos, sem quaisquer condições de vida e de sustentabilidade. Invoca-se o progresso para exterminar ou expulsar milhões de pessoas de seus territórios, agravando a miséria do Sul global e configurando a geopolítica do poder (Becker, 2005; Shiva, 1988).

O território de exclusão aqui estudado se localiza em Cubatão, na Baixada Santista de São Paulo. Segundo o Índice Paulista de Vulnerabilidade Social $^{5}$ (IPVS), em 2010, 21,2\% da população de Cubatão estava em situação de alta vulnerabilidade, e 21\% em situação de altíssima vulnerabilidade, em absoluta exclusão social (São Paulo, 2010). Cubatão foi construída sobre manguezais, o que trouxe desafios à urbanização. A principal fonte econômica da cidade são as indústrias petroquímicas, instaladas no mesmo período da construção de rodovias como a Anchieta, no final dos anos 1940 e início dos 1950. Sem escolha, trabalhadores permaneceram ali e surgiram as primeiras vilas operárias (Anhas; Silva, 2017).

No território, há uma USF, com três equipes de saúde da família. O Conselho Municipal de Saúde registra em torno de 40 mil famílias em moradias subnormais, como palafitas ou residências sem saneamento básico ou energia elétrica, com renda precária ou nula. Há uma creche, organizações de base comunitária e uma igreja (Anhas; Silva, 2017).

No local há uma cava subaquática, uma cratera de 400 metros de diâmetro e 25 metros de profundidade, aberta no meio do manguezal, fonte de contaminação e de riscos de acidente (O que..., 2018). Líderes comunitárias apontam a gravidade da situação ambiental no território, onde, além da cava, não há coleta de lixo, o que resulta em lixo abandonado em qualquer lugar:

$\varepsilon$ interessante falar em meio ambiente em lugar normal, mas nas palafitas... Quem mora em um barraco não tem lugar para guardar o material de reciclagem. Há uma grande distância para levar tudo até as caçambas. [Mas] agora nós temos duas mulheres à frente da associação e [isso] pode melhorar. (Ángeles)

A ausência da coleta de lixo aumenta a presença de animais sinantrópicos, causadores de doenças e de desfechos como amputação de membros de bebês mordidos por ratos. Essas são consequências da necropolítica do sistema capitalista, pois, no processo de globalização neoliberal, é sobre as crianças e as mães que o peso recai (Shiva, 1988), numa típica situação de interseccionalidade. A esperança de Ángeles é que as novas líderes eleitas consigam efetivar, junto ao poder público, as melhorias socioambientais.

Como aponta um dos interlocutores, Abdias, "tudo interfere na saúde, nas condições de vida. Quem mora na palafita, a maré enche, enche o barraco. Quando a maré enche, o rato vai pra dentro de casa". A fala evidencia que a saúde está abaixo dos padrões estabelecidos como direitos básicos, quadro que ainda se agravou durante a pandemia (Marques et al., 2020). A complexidade sociopolítica e econômica desse território de exclusão social demonstra as marcas coloniais mantidas pelo capitalismo neoliberal e pela geopolítica do poder, com pouca reparação ao longo dos séculos. 


\section{Desafios da colonialidade que fragilizam o cuidado}

A colonialidade e o capitalismo afetam o cuidado no território estudado. A fragilização pode ser observada a partir da EC 95, que direcionou o investimento em saúde, ciência e educação para o setor econômico, sucateando políticas públicas e revogando Programas de Atenção Básica (Fiocruz, 2020). Os cortes de orçamento dos Núcleos Ampliados de Saúde da Família (Nasf), a partir da Nota Técnica no 3/2020-DESF/ SAPS/MS, explicitam a restrição aos atendimentos da equipe multidisciplinar (Fiocruz, 2020): "Um senhor da minha área caiu e precisa de fisioterapeuta domiciliar. Falei pra ele: 'Olha, a sua vez na fisioterapia chegou, mas tem que ir até [o centro de] Cubatão'. Como ele vai até lá?" (Amy).

A agente comunitária Minerva demonstra consciência política ao questionar cortes de políticas públicas e denunciar a piora para os trabalhadores e excluídos, contrapondo a situação aos salários dos governantes e aos privilégios das elites: "Cortaram a verba, né? Da saúde, da educação, as áreas que mais precisam. Por que não cortam a deles?"

Devido às restrições para conter o contágio, a covid-19 agravou fragilidades interseccionais já existentes, relativas ao cuidado e ao meio ambiente. A pandemia expôs a impossibilidade de se cumprir medidas sanitárias em moradias subnormais e no transporte público lotado. Aumentaram ainda as mazelas anteriores à pandemia, como desemprego, fome, pobreza, violência e adoecimento (Portela et al., 2020).

Dói o coração, a gente sai arrasada. Se for ajudar todo mundo que precisa de comida... Fomos na casa duma mulher. A casa não tinha porta. A menina fica sozinha, roubam coisas dela. Ela diz: "Só consigo trabalhar de faxina. Ou a gente come ou...”. Dói e não podemos fazer nada! Não tem respaldo da Prefeitura! (Benguela)

O adoecimento da população se deve a condições precárias, exposição a diversas violências e carência de políticas públicas, podendo culminar até em suicídio. Na pobreza e no descaso político, o suicídio aparece como saída para interromper a dor gerada pela ausência de direitos básicos que garantem o bem viver: alimento, moradia, emprego e perspectiva de futuro (Pintasilgo, 2011). Nesse contexto, portanto, o autoextermínio resulta da falta de cuidado que aniquila a existência do sujeito.

Acredito que o ambiente faz as pessoas entrarem em depressão! A pessoa não tem uma casa legal, não tem o apoio dos pais, está procurando emprego e não consegue, tem filho e não recebe pensão. Acho que isso sim faz a pessoa adoecer! (Gamarra)

O aumento do adoecimento psíquico durante a pandemia evidenciou a importância da capilaridade do SUS e do cuidado multidisciplinar no território.

Grandes desafios para o cuidado ético-político são a violência e a fome, heranças coloniais e patriarcais mantidas pelo capitalismo neoliberal. A líder Ángeles relata que as mulheres, em boa parte negras, foram obrigadas a seguir com suas múltiplas jornadas durante a pandemia, sem ninguém para cuidar de seus filhos e familiares. As patroas não as liberaram, restando-lhes utilizar transporte lotado, muitas vezes tendo que levar os filhos ao local de trabalho, expondo a família ao risco de contágio:

Você vê de manhã as mulheres saindo pra trabalhar, recebendo telefonemas: "Ó, tem que ir". Não deixaram de trabalhar. Não teve esse apoio das patroas: "Ó, fica em casa". Muita gente ficou desempregada nessa pandemia. (Ángeles)

A fome e a violência, agravadas pela pandemia, aparecem com elevada frequência na fala de líderes e agentes comunitários de saúde, corroborando dados da Organização das Nações Unidas (ONU..., 2020). Há casos de violência doméstica que duram anos e causam sofrimentos tão insuportáveis que levam as vítimas ao suicídio, uma vez que o poder público e as políticas atuais não as alcançam. A interseccionalidade mostra diversas mulheres nas encruzilhadas de exclusões patriarcais da colonialidade (Akotirene, 2019). A maioria delas é preta, com renda nula (IBGE, 2020).

Elas se cansam de apanhar, algumas tomam remédio. $\varepsilon$ a gente sabe por que tomou remédio: pra se matar por causa do marido. Tínhamos uma 
funcionária, a Argelia. Apanhava de cinta. Ele mandava tirar a roupa e [ela] apanhava de cinta. Ela nunca contou pra gente. Ela lavava a louça e chorava. (Petra)

Líderes e agentes comunitários relatam que o silenciamento das vítimas de violência doméstica dificulta as intervenções de cuidado. " $E$ a gente fala: 'Mãe, por que não pediu socorro?'. 'Tenho vergonha, não queria me expor". (Petra). A impotência também é sentida nos casos de feminicídio, o assassinato de mulheres por serem mulheres. As vítimas, abandonadas pelo poder público, ficam sem cuidado algum:

Ela falava: "Não me mata, deixa eu criar a minha filha, não me mata, deixa eu criar a minha filha". Matou ela. Ele criou a menina. A filha não sabe disso até hoje. [Ela] tá com 12 anos. Foi falado que a mãe sumiu. Foi o pai. (Petra)

Operacionalizar o cuidado ético-político em casos de violência doméstica e feminicídio, que aumentaram subitamente, é um desafio para as teias de acolhimento (Marques et al., 2020): "Na pandemia aumentou muito o número de mulheres agredidas. Não tem onde recorrer porque os espaços [de cuidado] estão fechados. Apanha e silencia. Antes ia para a USF. Agora não tem estes espaços" (Ángeles); " $\varepsilon$ difícil sermulher no bairro pelas violências. Uma saída é participar da vida religiosa" (Barreto). A alternativa religiosa, porém, não é isenta de julgamentos patriarcais.

Outro desafio é a violência contra crianças, como pedofilia. Com o fechamento das escolas, as vítimas ficaram isoladas com seus agressores. "Tem muita pedofilia! Vejo vários, que nem imagino. Depois penso: não vou me meter, não posso fazer nada!" (Amy). A pandemia restringiu serviços, reduzindo os locais de acolhimento para vítimas de violência infantil e de gênero. As agentes comunitárias de saúde se sentem impotentes:

Vimos [que] o menino chegava aqui marcado. Um dia ele tava brincando com a irmãzinha, pisou no pezinho [dela]. O padrasto deu-lhe uma surra que marcou ele todinho. Falei "meu Deus do céu, não posso deixar". Ao mesmo tempo falei pro menino que não ia contar pra ninguém. (Petra)
Após cinco meses de pandemia, foi aprovada a Lei $\mathrm{n}^{0}$ 14.022/2020, que dispôs sobre ações de combate à violência doméstica e ao feminicídio (Brasil, 2020). A partir dela, o atendimento a ocorrências passou a funcionar ininterruptamente, de modo presencial, on-line ou por telefone, e campanhas de conscientização foram promovidas.

Outro problema relatado é o preconceito racial, crime inafiançável e imprescritível, conforme a Lei $n^{0} 7 \cdot 716 / 1989$, mas que perdura como violência estrutural contra negros e indígenas (Brasil, 1989). "O problema é quando vem a polícia. Anteontem veio e deu uns tiros aí. Os meninos correram que nem doido" (Petra). O Estado, que deveria proteger, torna-se agressor, dilacerando famílias:

A pessoa tem barraquinho nas palafitas, mora sozinha, deixa fechado e vai trabalhar. Tem invasão da polícia, a molecada corre pros mangues $e$ se esconde! A polícia vê o barraquinho, arrebenta a porta pensando que tem gente escondida. (Abdias)

Há ainda a violência do tráfico: "Conflitos são resolvidos pelo tráfico. A comunidade não pode exceder na resolução de problemas, para não chamar atenção da polícia" (Barreto); "Quando acontece alguma coisa, não podemos chamar a polícia. Pra nós, cristãos, fica pesado" (Petra). A lei do silêncio proíbe moradores de contatar agentes de segurança pública, dificultando o combate ao crime e à violência, naturalizando a impunidade e fragilizando o cuidado ético-político. A ausência de cuidado por parte do Estado abre portas para outras formas de poder patriarcal, como religião e tráfico.

$O$ cuidado na adolescência é outro desafio. $\mathrm{O}$ aborto desamparado, como em todo o Sul Global, é um grave problema para a saúde pública, principal causa de mortalidade materna, e entre as mulheres afetadas as negras são maioria (Coelho, 2019). "[Adolescente] pega muita gravidez, tem aquelas que faz [em] aborto" (Barreto). Devido à criminalização, crianças acabam levando a gravidez a termo, sendo mães ainda na infância. Outras, que tentam o aborto clandestino, muitas vezes acabam morrendo. "[No] tráfico, usar drogas e sexualidade precoce [é comum]. Se passar num baile [funk], [você] vê meninas fazendo sexo. Sífilis... A Lélia engravidou com 13 anos. 
A Mara [com] 13" (Petra). Nesse contexto, a cultura missionária, ligada a preceitos comportamentais patriarcais, surge como suposta salvação, para que jovens não entrem na criminalidade: "Me fiz essa pergunta: 'Pra que estou aqui?'. Aí quando chega um e fala 'tia, consegui', vocêfala: 'Se você não conseguiu salvar todos, pelo menos um você conseguiu'. Saiu [da criminalidade]" (Petra). Igrejas aparecem como refúgios provisórios e restritos, com regras internas. Elas podem se aproveitar da vulnerabilidade para aumentar seu lucro e impor comportamentos submissos à violência e ao patriarcado.

As falas evidenciam que os cortes de investimento em saúde, assistência e previdência prejudicaram o cuidado e a operacionalização das políticas públicas, aumentando a sobrecarga de líderes comunitários na medida que o Estado não assume o cuidado político-democrático. O problema se acentuou na pandemia, com a restrição do cuidado pelo SUS e o fim do Auxílio Emergencial a partir de janeiro de 2021, sem previsão de vacinação ampla.

\section{0 cuidado ético-político e as potências no território}

Ferramenta de combate à colonialidade, o cuidado acolhe excluídos, valoriza saberes e práticas locais e tece redes solidárias na comunidade. A busca do cuidado ético-político, com garantia de direitos, responsabilidade do Estado e da população, potencializa o cuidado efetivo, humanizado, transformador de estruturas, baseado nas diretrizes e princípios do SUS.

As teóricas feministas, ao afirmarem que o cuidado é importante para a sociedade, valorizam socioeconômica e moralmente esse trabalho e retiram as mulheres da invisibilidade. Por isso, incluir a interseccionalidade gênero, etnia, classe, história colonial e política - é fundamental. Valorizar o cuidado como direito é garantir o bem-estar social, em contraponto à colonialidade e ao capitalismo neoliberal, que o veem como produto ou dever da mulher.

As potencialidades observadas no território estudado foram: articulações coletivas, busca por equipamentos públicos, esforços para superar a exclusão social, consciência sobre direitos, interseccionalidade e políticas públicas e valorização dos próprios saberes e práticas. 0 cuidado perpassa ações ético-políticas nas organizações comunitárias e na intervenção com equipamentos do Estado.

$\mathrm{O}$ acesso a informações relacionadas à saúde coletiva, por meio do direito e da legislação, traria transformações estruturais para o território:

Líderes comunitários destacaram a importância de conscientizar a população sobre os riscos a que estão expostos devido à presença das cavas para descarte de lixo de metais pesados por empresas que dizem buscar o progresso, porém degradam o meio ambiente e afetam a vida. (Diário de Campo, $1^{\circ} \mathrm{de}$ fevereiro de 2018)

Saber nossos direitos, de receber esse auxílio [recompensa pela contaminação da água dos pescadores]. As pessoas não se interessam em conhecer seus direitos. (Barreto)

A colonialidade capitalista extrativista explora e destrói o meio ambiente. Populações são privadas de recursos naturais e têm sua existência anulada em prol do capital (Shiva, 1988). Informações sobre cuidado conscientizariam as pessoas sobre destruição ambiental, prevenção de doenças e campanhas de vacinação. A covid-19, nesse contexto, atualiza a discussão sobre o prejuízo das narrativas neoliberais e do negacionismo científico, que contribuem para o alastramento da doença (Lima et al., 2020): "Você vacina porque teve um grupo de pessoas que ficou doente passou naquele hospital, fez aquele relatório [um relatório foi feito], que levou pro Ministério da Saúde [o relatório foi encaminhado ao ministério], [e] lá eles tomaram a providência" (Barreto).

$\mathrm{O}$ acesso a fontes seguras de informação potencializa o cuidado ético-político. Nesse sentido, a atuação das mulheres para efetivar as mudanças no território é imensurável, desde a conscientização até a organização de atos e propostas de projetos de lei para a Câmara Municipal, demonstrando como a ética do cuidado, a interseccionalidade e o ecofeminismo atravessam suas práticas. "Conversando com algumas mulheres aqui da rua, estamos formando uma comissão pra ir à biqueira [território do tráfico], conversar sobre o baile funk que estão fazendo aqui" (Petra) 
A articulação das mulheres potencializa o cuidado ético-político também por meio de equipamentos de Estado:

Evangelina ligou [e avisou] que o pai tá maltratando [ela], em cárcere privado... Acionamos o Conselho Tutelar. Rigoberta foi na casa, tirou a menina, colocou no abrigo. Agora a mãe entrou em contato com a gente. (Petra)

As líderes comunitárias combatem violências interseccionais ativamente. Por morarem no território, conhecem a história dos moradores e podem acionar os equipamentos de Estado, acompanhar a evolução dos casos e fomentar a emancipação de outras mulheres. "Fizemos ela denunciar. Ela denunciou, ele foi tirado pra fora de casa pela polícia... Hoje a Argelia está bem, trabalhando aqui com a gente" (Petra).

No cuidado do direito habitacional, a articulação de mulheres iniciou a ocupação de terrenos, a construção de moradias e o avanço do território por vias políticas e judiciais:

Ela falou que, quando veio pra cá, era tudo área de invasão, mato! Um grupo de mulheres se reuniu, fechou a pista velha que hoje é a Tancredo. O prefeito da época forneceu carros com aterros e fizeram a urbanização. (Petra)

As intervenções da Unifesp também potencializam o cuidado ético-político. De um ponto de vista decolonial, os saberes coexistem. Lugones (2014) explica que a decolonialidade pretende libertar as ciências e as práticas do Sul global da colonialidade e das elites intelectuais, centradas nas epistemes europeias e norte-americanas e no capital. "Psicóloga da Unifesp pode chegar, fazer a roda [de conversa],trazemos pessoas e acabamos usando vocês, como o suporte que deveria ter pela Prefeitura" (Benguela).

A USF configura espaço de cuidado éticopolítico garantido por lei. "A gente agradece a Deus, mesmo com dificuldades temos a USF aqui” (Petra). Os profissionais valorizam a capilarização e o trabalho em equipe da atenção primária à saúde, com integralidade do cuidado: o médico da família reforçou que é necessário retirar a visão médico-centrada, valorizando outros profissionais. Somente assim será possível prestar atendimento integral à população. (Oficina DiverSUS, realizada em 2019)

Agentes comunitários e líderes mostram-se conscientes da importância de práticas de cuidado, reforçando a relevância da pedagogia popular e do papel da saúde da família: "A importância de conscientizar a população sobre o papel do serviço da saúde da família [serviço do SUS], ressaltando ofator educação em saúde" (Abdias); "É preciso investir em educação popular e romper com as políticas de favor [clientelismo]. A comunidade tem que saber seus direitos, legislação e deveres" (Ángeles). Ao compreenderem o que é melhor para si, as pessoas se fortalecem como cidadãs plenas, lutando pelo bem viver e pela transformação estrutural desse território de exclusão social.

\section{Considerações finais}

A compreensão do cuidado perpassou três zonas de sentido: a apresentação sócio-histórica, interseccional e ambiental do território; os desafios da colonialidade que fragilizam o cuidado; e o cuidado ético-político e as potências do território. Olhar o cuidado possibilitou refletir sobre direitos humanos e ambientais e políticas públicas no território estudado. Os desafios percebidos decorrem da absoluta exclusão social das pessoas que ali vivem (dentre elas, as mulheres negras são as mais atingidas) sem direitos básicos e abandonadas pelo poder público, em insegurança alimentar e habitacional. A covid-19 agravou a situação: violência doméstica, feminicídio, pedofilia, adoecimento mental e suicídios.

Observa-se que o cuidado ético-político poderia potencializar o enfrentamento à covid-19 e aos demais desafios estruturais do território. 0 trabalho multidisciplinar da atenção primária precisa ser fortalecido. Líderes e agentes comunitários de saúde se mostraram conscientes, propositivos e capazes de produzir práticas e saberes específicos para as demandas da comunidade.

As categorias feministas de ética do cuidado, ecofeminismo e interseccionalidade demonstram sua 
relevância neste contexto ao ajudar a compreender criticamente o modus operandi do cuidado na colonialidade. As teóricas feministas desses campos propõem que o ato de cuidar garante direitos e uma política democrática, oferecendo recursos para remodelar as estruturas socioambientais.

É urgente reler a colonialidade mantida pela modernidade capitalista patriarcal através das lentes da ética do cuidado, que relaciona questões socioambientais, econômicas, jurídicas e governamentais a saberes e práticas de cuidado. Trata-se de lentes que permitem ver o que se esconde das compreensões sobre interseccionalidades de raça, gênero e classe, bem como as relações de normatividade e hegemonia do grande capital patriarcal, que estruturalmente explora e nega o cuidado. Assim, de um ponto de vista éticopolítico, é preciso enxergar que mulheres que cuidam propõem saídas para o bem viver por meio de políticas públicas e da democracia.

\section{Referências}

AKOTIRENE, C. Interseccionalidade. São Paulo: Sueli Carneiro; Pólen, 2019.

ANHAS, D. M.; SILVA, C. R. C. C. Participação social e subjetividade: vivências juvenis em uma comunidade vulnerável. Psicologia: Teoria e Prática, São Paulo, v. 19, n. 3, p. 139-148, 2017.

BECKER, B. K. Geopolítica da Amazônia. Estudos Avançados, São Paulo, v. 19, n. 53, p. 71-86, 2005.

BRASIL. Lei $n^{0} 7 \cdot 716$, de 5 de janeiro de 1989. Define os crimes resultantes de preconceito de raça ou de cor. Diário Oficial da União, Brasília, DF, 6 jan. 1989. Disponível em: <https://bit.ly/3dB57Tb>. Acesso em: 9 dez. 2020.

BRASIL. Portaria $\mathrm{n}^{0}$ 3.124, de 28 de dezembro de 2012. Redefine os parâmetros de vinculação dos Núcleos de Apoio à Saúde da Família (NASF), e dá outras providências. Diário Oficial da União, Brasília, DF, 31 dez. 2012. Disponível em: <https://bit.ly/3uqVQnA>. Acesso em: 9 dez. 2020.

BRASIL. Senado Federal. Lei torna essenciais serviços de combate à violência doméstica.
Brasília, DF, 8 jul. 2020. Disponível em: <https://bit.ly/3wGZY4O>. Acesso em: 3 ago. 2020.

CARVALHO, C. C. B. Equidade de gênero na ciência?: um estudo sobre as pesquisadoras bolsistas de produtividade da Universidade Federal de São Carlos (UFSCar). 2016. Dissertação (Mestrado em Gestão de Organizações e Sistemas Públicos) - Universidade Federal de São Carlos, São Carlos, 2016.

CHAUI, M. Brasil: mito fundador e sociedade autoritária. São Paulo: Fundação Perseu Abramo, 2009.

COELHO, J. Negritude: direitos sexuais e reprodutivos. In: MELO, P. B. et al. Descolonizar o feminismo. Brasília, DF: Editora IFB, 2019. p. 140-153.

COLLINS, P. H. Se perdeu na tradução? Feminismo negro, interseccionalidade e política emancipatória. Parágrafo, São Paulo, v. 5, n. 1, p. 6-17, 2017.

CRENSHAW, K. Demarginalizing the intersection of race and sex: a black feminist critique of antidiscrimination doctrine, feminist theory and antiracist politics. University of Chicago Legal Forum, n. 1, p. 139-167, 1989. Disponível em: <https://bit.ly/3tiGdhz>. Acesso em: 14 abr. 2021.

DANTAS, A. V. Coronavírus, o pedagogo da catástrofe: lições sobre o SUS e a relação entre público e privado. Trabalho, Educação e Saúde, Rio de Janeiro, v. 18, n. 3, eoo281113, 202O. DOI: 10.1590/1981-7746-soloo281

DAVIS, A. Mulheres, raça e classe. São Paulo: Boitempo, 2016.

FIOCRUZ - FUNDAÇÃO OSWALDO CRUZ. Saúde da Família perde modelo do NASF. Rio de Janeiro, $1^{\circ}$ mar. 2020. Disponível em: <https://bit.ly/31NQPsH>.

Acesso: 9 dez. 2020.

FORTE, E. C. N. et al. A hermenêutica e o software Atlas.TI: união promissora. Texto \& Contexto Enfermagem, Florianópolis, v. 26, n. 4, e0350017, 2017. DOI: 10.1590/0104-07072017000350017

GONZALEZ, L. Racismo e sexismo na cultura brasileira. Revista Ciências Sociais Hoje, São Paulo, p. 223-244, 1984. 
HALE, C. R. Racismo cultural. Ciudad de

Guatemala: Avancso, 2004.

IBGE - INSTITUTO BRASILEIRO DE GEOGRAFIA E ESTATÍSTICA. Cidades@: São Paulo: Cubatão.

Rio de Janeiro, 2020. Disponível em:

<https://bit.ly/3rVEtJE $>$. Acesso em: 3 ago. 2020.

LIMA, C. R. M. et al. Emergência de saúde pública global por pandemia de covid-19: desinformação, assimetria de informações e validação discursiva. Folha de Rosto, Juazeiro do Norte, v. 6, n. 2, p. 5-21, 2020. DOI: 10.46902/2020n2p5-21

LUGONES, M. Rumo a um feminismo descolonial. Revista Estudos Feministas, Florianópolis, v. 22, n. 3, p. 935-952, 2014. DOI: 10.1590/So104$026 \mathrm{X} 2014000300013$

MARQUES, E. S. et al. A violência contra mulheres, crianças e adolescentes em tempos de pandemia pela covid-19: panorama, motivações e formas de enfrentamento. Cadernos de Saúde Pública, Rio de Janeiro, v. 36, n. 4, eooo74420, 2020. DOI: 10.1590/0102-311x00074420

MBEMBE, A. Necropolítica. São Paulo: N-1 Edições, 2018.

MOTA, F. F. Joan C. Tronto: Caring democracy: markets, equality, and justice. Revista Brasileira de Ciência Política, Brasília, DF, n. 18, p. 317-327, 2015. DOI: 10.1590/0103-335220151812

NASCIMENTO, M. B. Sistemas sociais alternativos organizados pelos negros: dos quilombos às favelas. In: NASCIMENTO, M. B. Beatriz Nascimento, quilombola e intelectual: possibilidades nos dias de destruição. [S. l.]: Filhos da África, 2018. p. 211-225.
ONU: violência sexual em conflitos se aprofunda durante pandemia. ONU Mulheres, Brasília, DF, 22 jun. 2020. Disponível em: <https://bit.ly/3mly89s>. Acesso em: 3 ago. 2020.

O QUE é a Cava Subaquática? Contra a Cava Submarina, [S. l.], 26 mar. 2018. Disponível em: <https://bit.ly/2PvDXoT>. Acesso em: 13 out. 2020.

PINTASILGO, M. L. Para um novo paradigma: um mundo assente no cuidado: antologia de textos de Maria de Lourdes Pintasilgo. Porto: Afrontamento, 2011.

PORTELA, M. C. et al. Nota técnica 1: limites e possibilidades dos municípios brasileiros para o enfrentamento dos casos graves de covid-19. Rio de Janeiro: Fiocruz, 2020.

SÃO PAULO. Fundação Sistema Estadual de Análise de Dados. IPVS - Índice Paulista de Vulnerabilidade Social. São Paulo, 2010. Disponível em: <https://bit.ly/2PHFgRo>. Acesso em: 9 dez. 2020.

SHIVA, V. Staying alive: women, ecology and survival. New Delhi: Zed Books, 1988.

SINGER, P.; SOUZA, A. R. (Org.). A economia solidária no Brasil: a autogestão como resposta ao desemprego. São Paulo: Contexto, 2000.

SOUZA, J. A elite do atraso: da escravidão a Bolsonaro. Rio de Janeiro: Estação Brasil, 2019.

THOMPSON, J. B. Ideologia e cultura moderna. 9. ed. Petrópolis: Vozes, 2011.

WHO - WORLD HEALTH ORGANIZATION. COVID-19 weekly epidemiological update. Geneva, 8 dez. 2020. Disponível em: <https://bit.ly/3sUGsj1>. Acesso em: 9 dez. 2020.

\section{Contribuição das autoras}

Camilo coletou e interpretou os dados, aprofundou os conceitos de decolonialidade, interseccionalidade e território de exclusão e escreveu o artigo. Schveitzer contribuiu com a definição da metodologia e delimitação da temática, além de ter recomendado artigos para a bibliografia. Ferreira ajudou a aprofundar as categorias cuidado, ética do cuidado e ecofeminismo. Kahhale revisou conceitos e categorias e deu sugestões para a discussão dos resultados, especialmente na parte sócio-histórica.

Recebido: 04/03/2021

Aprovado: 16/03/2021 